\title{
Diploscapter CORONATA (COBB, 1893) INFESTATION IN CAPTIVE SNAKES
}

\author{
Lucy Sabu ${ }^{1}$, K. Devada, H. Subramanian and Jacob V. Cheeran
}

College of Veterinary and Animal Sciences, Mannuthy, Thrissur, Kerala, India.

${ }^{1}$ Email: lucysabu_in@yahoo.com

\begin{abstract}
Cutaneous nodules were noticed on the body of captive snakes. The contents of the nodules were necrotic and on microscopic examination revealed the presence of mites, their developmental stages and a myriad of free living nematode Diploscapter coronata and their eggs and larvae.
\end{abstract}

\section{Keywords}

Diploscapter coronata, infestation, snakes

\section{Introduction}

Diploscapter coronata is a cosmopolitan Rhabditid nematode identified for the first time from decaying banana roots in Fiji. The nematode has been collected largely from soil and decaying plant material by many scientists from time to time (Thorne, 1961). The only report available on the presence of $D$. coronata in vertebrate host is in the stomach of humans (Chandler, 1938). This paper describes the infestation of captive snakes by the nematode, Diploscapter coronata.

\section{Case history}

Six captive snakes consisting of three cobras and three rat snakes, belonging to the Government Snake Park, Malampuzha, Palakkad District $\left(10^{\circ} 46^{\prime}-10^{0} 59^{\prime} \mathrm{N}\right.$ to $76^{0} 28^{\prime}-76^{0} 39^{\prime} \mathrm{E}$ having humid tropical climate), Kerala, India were brought to the Department of Veterinary Parasitology, College of Veterinary and Animal Sciences. They were reported to be off-feed for several months and were being force-fed egg yolk. A few snakes had already succumbed to illness during the previous months.

\section{Observations}

Close and careful examination of the body of the snakes revealed the presence of several nodules with diameter of up to $1 \mathrm{~cm}$ on the external surface which could be easily palpated (Fig. 1). It was said that when the snakes moulted, these nodules also detached exposing the tissue underneath.
Faecal samples from all the snakes on microscopical examination were found to contain large numbers of ova of Ascarid, Strongyle and Capillaria sp. besides numerous nematode larvae.

The cutaneous nodules were dissected out and examined microscopically, after crushing the caseated necrotic tissue. Several mites, mite eggs and a myriad of nematodes of varying sizes and their ova (Fig. 2) were detected. Based on the morphology and micrometry the mites were identified as Ophionyssus natricus and the nematode as Diploscapter coronata. Gravid female worms (Fig. 3) and moulting nematodes (Fig. 4) were also noticed in the contents.

\section{Description}

Ophionyssus natricus Camin, 1953, is red, grey or black and approximately $1 \mathrm{~mm}$ long. It is found between and under the scales of snakes especially in the areas of the chin, eye and cloaca (Kettle, 1995). In the present case the mites and their developmental stages were detected in the necrotic mass inside the cutaneous nodules (Fig. 5).

Diploscapter coronata belongs to the Rhabditidae family. Dorsal and ventral lips are modified into sclerotised hook-like fosseres (diggers). Lateral lips are modified into fringed sclerotised projections. Oesophagus is with posterior bulb. The females measured $387-450 \mu(425)$ with a maximum width of $40 \mu$. Uterus amphidelph with genital pore in the posterior half is much above the anus. The length of larvae which included L1, L2, L3 and L4 ranged from $138-305 \mu$. The ova were thin walled elongate oval with blunt ends, fully embryonated and measured $34 / 22 \mu$.

The snakes were administered ivermectin @ $0.2 \mathrm{mg} / \mathrm{kg}$ body wt. as $\mathrm{S} / \mathrm{C}$ injection after diluting with propylene glycol. As it was understood that the snakes acquired infections of nematodes and mites repeatedly from the soil of their enclosures, the caretakers were advised to change the sand and disinfect the enclosures/cages regularly. 


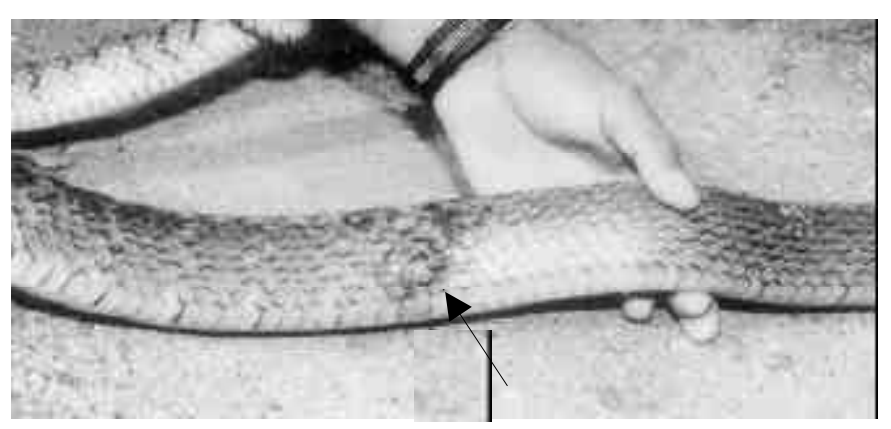

Figure 1. Cutaneous nodule with necrotic mass on a rat snake

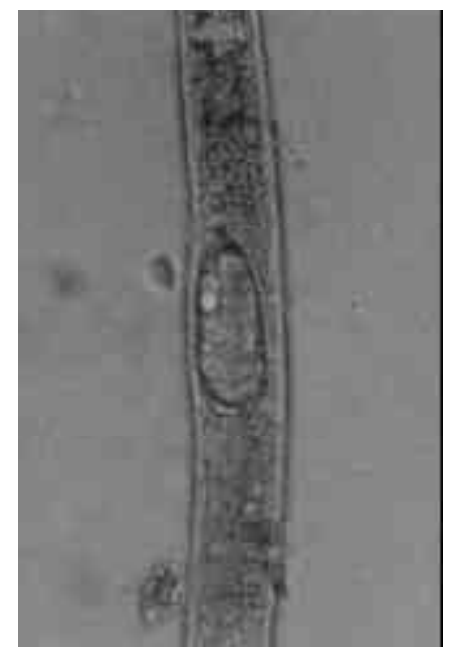

Figure 3. Gravid female D. coronata. Egg in the uterus. x1000

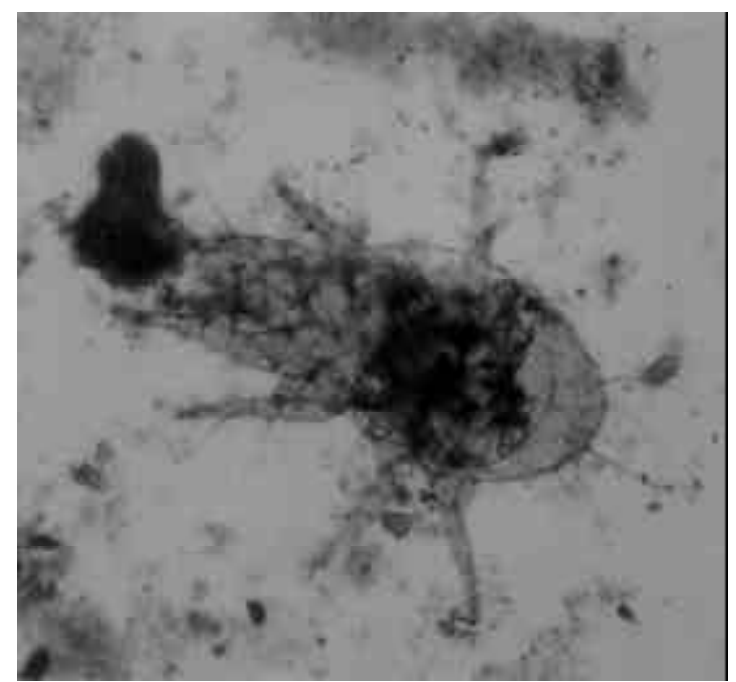

Figure 5. Adult Ophionyssus natricus found in the necrotic contents. $x 400$

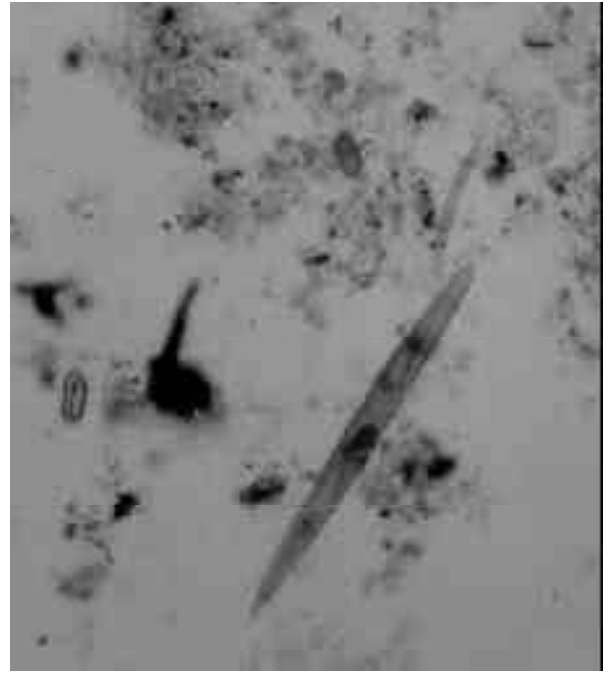

Figure 2. Adult female, larva and eggs in the necrotic contents $x 100$

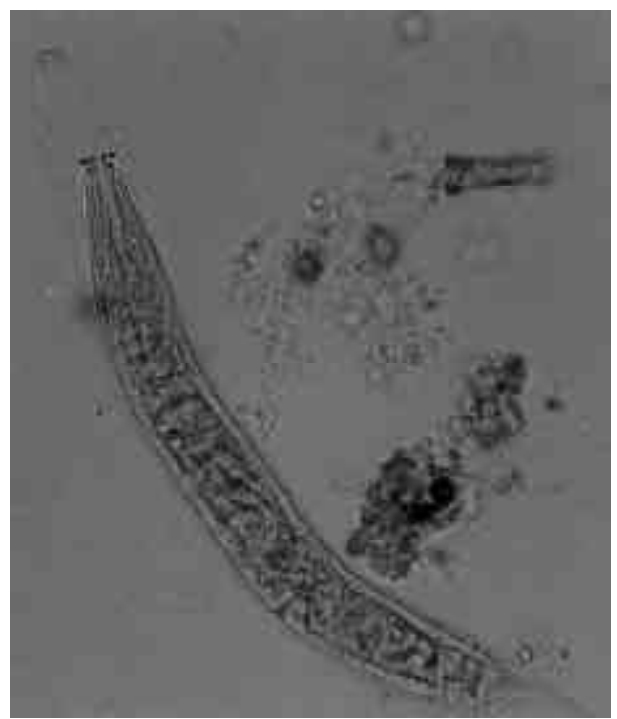

Figure 4. Moulting larva. The sheath of the previous stage and the fringed sclerotized lateral lips are visible at the head end. $x 400$ 
On a visit to the snake park two months later, it was learnt that the condition of the snakes had improved markedly even though a few snakes had died in the meantime. However, cutaneous swellings were noticed on the body of some of them, which were dissected out and examined. During this time none of the nodules were found to contain any nematode, mites or any of their developmental stages.

\section{Discussion}

Cutaneous swellings and severe necrotic lesions caused by Macdonaldius oschei a filaria of new world snakes have been described in captive Asiatic python (Reichenbach-Klinke \& Elkon, 1965). But those are larger viviparous filarid worms measuring more than $50 \mathrm{~mm}$, whereas $D$. coronata encountered in the present case is less than $500 \mu$.

Infections with massive burdens of mites and endoparasites in the snakes as a result of infected sand in the limited space available inside the enclosures coupled with reduction in feed intake would have probably minimised their innate immunity. This would have made the snakes moribund and subsequently the free living $D$. coronata would have invaded and multiplied in the tissues. Administration of ivermectin which is an endectocide that act against nematodes and mites and the adoption of better managemental practices helped to prevent reinfections to a great extent. The condition of the snakes was found to improve following treatment, preventing the survival of the free living organisms in the necrotic tissue.

Cutaneous noolules infected $w$ ith soil nem atode $D$. coronata leading to mortality in captive snakes is reported for the first time.

\section{Acknowledgements}

The authors are thankful to the Dean, College of Veterinary and Animal Sciences, Mannuthy for the facilities provided. Thanks are also due to Dr. C.T. Faulkner, University of TN Veterinary Teaching Hospital, USA for the co-operation extended in identifying the parasite.

\section{References}

Chandler, A.C. (1938). Diploscapter coronata as a facultative parasite of man, with a general review of vertebrate parasitism by rhabditoid worms. Parasitology 30: 44-45. (Original not consulted).

Kettle, D.S. (1995). Pp. 431-433. Medical and Veterinary Entomology. $2^{\text {nd }}$ edition. CAB International.

Reichenbach-Klinke, H. and E. Elkan (1965). pp. 463-468. The Principal Diseases of Lower Vertebrates. Academic Press, New York. Thorne, G. (1961). pp. 458-461. Principles of Nematology. McGraw Hill Book Co., New York. 